\title{
No evidence for immunoproteasomes in chicken lymphoid organs and activated lymphocytes
}

\author{
Sonja Erath • Marcus Groettrup
}

\begin{abstract}
The proteasome is the main protein-degrading machine within the cell, producing ligands for MHC class I molecules. It is a cylindrical multicatalytic protease complex, and the catalytic activity is mediated by the three subunits $\beta 1$, $\beta 2$, and $\beta 5$ which possess caspase-, trypsin-, and chymotrypsin-like activities, respectively. By stimulation with interferon (IFN)- $\gamma$ the replacement of these subunits by $\beta 1$, $\beta 2 \mathrm{i}$, and $\beta 5 \mathrm{i}$ is induced leading to formation of immunoproteasomes with altered proteolytic and antigen processing properties. The genes coding for these immunosubunits are restricted to jawed vertebrates but have so far not been found in the genomes of birds, e.g., chicken, turkey, quail, black grouse and zebra finch. However, the chicken genome sequences are not completely assigned; therefore, we investigated the presence of immunoproteasome on protein level. $20 \mathrm{~S}$ proteasome was purified from the chicken brain, blood, spleen, and bursa of Fabricius, followed by separation via two-dimensional (2D) gel electrophoresis. We analyzed the protein spots derived from the spleen and brain by mass spectrometry and could identify all 14 proteasomal subunits, but there were no differences detectable in the spot patterns. Moreover, we stimulated the chicken spleen cells with phorbol 12-myristate 13-acetate (PMA) and ionomycin aiming at the induction of immunoproteasome, but in spite of the induction of proliferation and IFN- $\gamma$, no evidence for immunoproteasome formation in chicken could be obtained. This result was substantiated by the finding that $20 \mathrm{~S}$ proteasomes isolated from immune and non-immune tissues
\end{abstract}

S. Erath $\cdot$ M. Groettrup $(\bowtie)$

Department of Immunology, University of Konstanz,

Universitaetsstrasse 10, 78464 Konstanz, Germany

e mail: Marcus.Groettrup@uni konstanz.de

M. Groettrup

Biotechnology Institute Thurgau at the University of Konstanz,

Unterseestrasse 47, 8280 Kreuzlingen, Switzerland showed very similar peptidolytic activities. Taken together, our results indicate that chicken lack immunoproteasomes also on protein level.

Keywords Proteasome $\cdot$ Immunoproteasome $\cdot$ Chicken . Galliformes $\cdot$ MHC locus $\cdot$ Bursa of Fabricius

\section{Introduction}

The proteasome is the major protein-degrading system in the nucleus and the cytoplasm, responsible for the clearance of misfolded proteins, transcription factors, or cell regulators. Proteins are tagged for proteasomal proteolysis by the conjugation to polyubiquitin or the ubiquitin-like modifier FAT10 (Hershko et al. 2000; Miteva et al. 2010; Schmidtke et al. 2014). The main form of proteasome is the so-called $26 \mathrm{~S}$ proteasome comprised of the cylindric $20 \mathrm{~S}$ core particle, responsible for the proteolytic activity, capped by the 19S regulator. The $20 \mathrm{~S}$ proteasome is barrel-shaped and consists of 28 subunits with masses of $20-30 \mathrm{kDa}$ arranged in four rings each comprising seven subunits (Huber et al. 2012). The two outer rings of the cylinder are called the $\alpha$ rings containing subunits $\alpha 1-7$ and the two internal $\beta$ rings contain subunits $\beta 1-7$. The $\beta$ rings possess the proteolytic activity which is mediated by the three different catalytic sites on subunits $\beta 1, \beta 2$, and $\beta 5$. Subunit $\beta 1$ is responsible for the caspase-like activity, $\beta 2$ for the trypsin-like activity, and $\beta 5$ for chymotrypsin-like cleavage activity of the proteasome, producing peptides with acidic, basic, and hydrophobic Cterminal residues, respectively (Kniepert and Groettrup 2014). The proteasome is constitutively expressed in most tissues. Through the treatment with the pro-inflammatory cytokines interferon (IFN)- $\gamma$ or tumor necrosis factor (TNF)- $\alpha$, a replacement of the three constitutive catalytic subunits by their inducible homologues $\beta 1 \mathrm{i}$ (PSMB9), $\beta 2 \mathrm{i}$ 
(PSMB10), and $\beta 5 \mathrm{i}$ (PSMB8) is initiated (Groettrup et al. 1996; Groettrup et al. 1995). This results in the formation of a protease called the immunoproteasome the expression of which is typically restricted to immune cells and has altered proteolytic properties. $\beta 1 \mathrm{i}$ favors cleavage after hydrophobic residues instead of acidic ones. Further, peptides generated by the proteasome are presented on MHC class I molecules but those originating from the immunoproteasome contain more suitable $\mathrm{MHC}$ class I ligands in mice and humans, because the binding groove has a higher binding affinity for peptides with hydrophobic or basic C-termini (Kaufman et al. 1995; Koch et al. 2007; Wallny et al. 2006). In this context, another type of proteasome should be mentioned, the thymoproteasome, which is characterized by the catalytic proteins $\beta 1 \mathrm{i}$ and $\beta 2 \mathrm{i}$ as well as $\beta 5 \mathrm{t}$ and is unique to cortical thymic epithelial cells (cTECs) residing in the cortex of the thymus. Thymoproteasome is critical for the positive selection and maturation of $\mathrm{T}$ cells by the production of low affinity MHC class I ligands (Murata et al. 2007).

Although the constitutive proteasome is found in almost all organisms (from plants over fungi to vertebrates), the immunoproteasome is principally found in mammals, fish, amphibians, and reptiles. BLAST search approaches in chicken, turkey, quail, black grouse, and zebra finch failed to detect genes for immuno- and thymoproteasome, suggesting that they have been lost in the lineage of birds (Balakrishnan et al. 2010; Chaves et al. 2009; Shiina et al. 2007; Shiina et al. 2004; Sutoh et al. 2012; Wang et al. 2012). While the genes coding for the catalytic subunits $\beta 1 \mathrm{i}$ and $\beta 5 \mathrm{i}$ are present in the class II region of the human and murine MHC loci, sequence searches in chicken genome databases revealed that there are no LMP genes in the avian MHC region, and also the immune subunit $\beta 2 \mathrm{i}$ could not be identified. All genes located in the chicken MHC locus do have human homologues, e.g., TAP genes, tapasin, complement component $\mathrm{C} 4$, but not all human MHC genes are present in chicken and the different gene class regions are organized in a different way (Kaufman 2008). The chicken MHC locus represents a minimized set of genes conserved over the period of evolution between aves and mammals (Kaufman et al. 1999). It can therefore not be ruled out that immunoproteasome genes have been lost from the chicken MHC locus and inserted elsewhere. Such genes may have remained unrecognized due to poor sequence conservation or due to holes in the chicken genome as it is currently known.

In order to investigate the presence of immunoproteasome in chicken on the protein level, we purified 20S proteasomes from different organs and analyzed them by two-dimensional (2D) gel electrophoresis followed by mass spectrometric analysis. Typical organs in chicken where immunoproteasome would be suspected are the spleen, thymus, and bursa of Fabricius, while it is assumed that the brain exclusively expresses constitutive proteasome and whole blood might be a mixture of both proteasomes, in which the constitutive one predominates. In contrast to the other organs, the bursa of Fabricius is a primary lymphoid organ for the production of $\mathrm{B}$ cells which is unique to birds. In humans, the differentiation of $B$ cells occurs in the bone marrow whereas birds use the bursa of Fabricius, which is located dorsal to the cloaca (RodriguezMendez et al. 2010). During embryonic days 4 to 8, the bursa is formed and afterwards colonized by B cells. Until sexual maturity at 4-6 months, it is the place of B cell differentiation. Subsequently, the bursa regresses completely and the B cells migrate to secondary lymphatic organs and the blood, from then on representing the peripheral B cell pool (Mustonen et al. 2001).

The goal of this study was to investigate the presence of constitutive and immunoproteasome in chicken on protein level. To this aim, 20S proteasomes were purified from different lymphatic organs in comparison to non-lymphatic organs and proteasomes were analyzed by 2D gel electrophoresis. Further, we determined the three different catalytic activities of the purified chicken proteasomes.

\section{Methods}

Purification of 20S proteasome from chicken organs

The purification of $20 \mathrm{~S}$ proteasome from the brain, whole blood, spleen, bursa of Fabricius, and thymus, retrieved from laying hens and broiler chickens, was performed as previously described (Basler and Groettrup 2012). Shortly, organs were lysed and homogenized and then centrifuged to remove cell debris. Overnight, negatively charged proteins were bound to DEAE Sephacel $^{\mathrm{TM}}$ (GE Healthcare), washed the next day, and eluted using $500 \mathrm{mM} \mathrm{KCl}$ buffer, $10 \mathrm{mM}$ HEPES, and $5 \mathrm{mM}$ $\mathrm{MgCl}_{2}, \mathrm{pH}$ 7.2. Fractions containing protein were pooled and precipitated with $35 \%$ ammonium sulfate; subsequently, the supernatant was adjusted to $80 \%$ ammonium sulfate; after centrifugation, the protein pellet was resolved and separated via a sucrose gradient (15-40\%) using an ultracentrifuge. Fractions which possess proteolytic activity were pooled and finally purified by FPLC (ÄKTA, GE Healthcare) using a Resource $^{\mathrm{TM}}$ Q 1-ml column (Amersham Pharmacia Biotech). Purifications were tested for proteasome activity, protein concentration, and purity by 2D gel electrophoresis. All animal work was conducted according to the German guidelines and was approved by the ethics committee of Regierungspräsidium Freiburg, Germany.

\section{D gel electrophoresis}

Purified chicken 20S proteasome was separated in a nonequilibrium $\mathrm{pH}$ gradient gel electrophoresis/sodium dodecyl sulfate polyacrylamide gel electrophoresis (SDS-PAGE) according to previous descriptions (Groettrup et al. 1996). 
Briefly, $60 \mu \mathrm{g}$ of purified proteasome was precipitated using $10 \%$ trichloroacetic acid and washed with ice-cold acetone and $100 \%$ ethanol. The precipitated proteasome was dissolved in $80 \mu \mathrm{l}$ sample buffer $(9.5 \mathrm{M}$ urea, $2 \% \mathrm{NP}-40,5 \%$ Servalyt ${ }^{\circledR}$ ampholines, pH 3-10 (Serva, Heidelberg, Germany), $0.3 \%$ SDS, and $5 \%$ 2-mercaptoethanol) during overnight shaking at a temperature of $28{ }^{\circ} \mathrm{C}$. Samples were loaded on 12-cm gel rods and were separated in a $2 \mathrm{D}$ gel apparatus (BioRad) along a $\mathrm{pH}$ gradient (anode: $0.01 \mathrm{M}$ $\mathrm{H}_{3} \mathrm{PO}_{4}$; cathode: $0.02 \mathrm{M} \mathrm{NaOH}$ ). For the second dimension, the gel rods were equilibrated and fixed to the top of a $15 \%$ SDS-polyacrylamide gel and afterwards $1100 \mathrm{Vh}$ were applied overnight and gels were stained with Coomassie blue.

Mass spectrometric analysis of purified chicken $20 \mathrm{~S}$ proteasome

Protein spots of interest were excised from the gels, and the pieces were incubated at $56{ }^{\circ} \mathrm{C}$ in $50 \mathrm{mM}$ ammonium bicarbonate containing $10 \mathrm{mM}$ DTT. After $1 \mathrm{~h}$, the solution was removed and $50 \mathrm{mM}$ iodoacetamide diluted in $50 \mathrm{mM}$ ammonium bicarbonate were added for another hour at room temperature. Before dehydration with $3 / 2$ acetonitrile/MilliQ, gel pieces were washed in MilliQ water and were incubated for $30 \mathrm{~min}$ in $50 \mathrm{mM}$ ammonium bicarbonate. Once the gels lost their color, they were incubated for $10 \mathrm{~min}$ with pure acetonitrile and were subsequently air dried. Gel pieces were rehydrated with cold $50 \mathrm{mM}$ ammonium bicarbonate containing $10 \mathrm{ng} / \mu \mathrm{l}$ trypsin $\left(45 \mathrm{~min}\right.$ at $\left.4{ }^{\circ} \mathrm{C}\right)$. To digest the proteins, the gel pieces were covered with $50 \mathrm{mM}$ ammonium bicarbonate and were incubated overnight at $37^{\circ} \mathrm{C}$. The peptides were eluted by adding 3/2 acetonitrile/ $0.1 \%$ trifluoroacetic acid for $1 \mathrm{~h}$ at room temperature and were dried in a vacuum centrifuge. Finally, the samples were dissolved and were analyzed by nano-LC-ESI-MS/MS using a Thermo LTQ Orbitrap Discovery with Eksigent 2D nano-HPLC. Subsequent identification of proteins was achieved by searching the Swiss-Prot database (UniProtKB/Swiss-Prot sequences).

Preparation of spleen single cell suspensions and LPS treatment

Dissected spleens from laying hens or broiler chickens were collected in $10 \mathrm{ml}$ cell culture medium (IMDM GlutaMAX supplemented with $10 \%$ FCS, $1 \%$ penicillin-streptomycin and $1 \%$ gentamicin, Gibco ${ }^{\circledR}$ Life Technologies, Karlsruhe, Germany) on ice. The single cell suspension was prepared by gently pushing the organ through a sterile steel grid; afterwards, cells were rinsed through a $70-\mu \mathrm{m}$ cell strainer (BD Falcon) and were washed twice with PBS (137 $\mathrm{mM} \mathrm{NaCl}$, $2.68 \mathrm{mM} \mathrm{KCl}, 8.1 \mathrm{mM} \mathrm{Na} \mathrm{HPO}_{4} \cdot 2 \mathrm{H}_{2} \mathrm{O}$ and $1.47 \mathrm{mM}$ $\mathrm{KH}_{2} \mathrm{PO}_{4}, \mathrm{pH}$ 7.2). Finally, cells were resuspended in culture medium and one half was directly spun down $(1300 \times \mathrm{g}$ for $10 \mathrm{~min}$ ) and the cell pellet was stored at $-20{ }^{\circ} \mathrm{C}$, while the other half was seeded into $15-\mathrm{cm}^{2}$ cell culture dishes and was incubated with $10 \mathrm{ng} / \mathrm{ml}$ phorbol 12-myristate 13-acetate (PMA) and $0.5 \mu \mathrm{g} / \mathrm{ml}$ ionomycin (Sigma-Aldrich), $10 \mu \mathrm{g} / \mathrm{ml}$ concanavalin A (Sigma-Aldrich), or $3 \mu \mathrm{g} / \mathrm{ml}$ lipopolysaccharides (LPS from Escherichia coli 0111:B4, Sigma-Aldrich). Every day, cell proliferation was analyzed by carboxyfluorescein succinimidyl ester (CFSE) dilution assay and flow cytometry. The upregulation of IFN- $\gamma$ was monitored by quantitative real-time RT-PCR using the primers ACTGGACAGA GAGAAATGAGAA and GTCGTTCATCGGGAGCTTGG. For normalization, the GAPDH primers GAAGGCTGGGGC TCATCTGAA and ATCATACTTGGCTGGTTTCTCC were used at an annealing temperature of $62{ }^{\circ} \mathrm{C}$. After 3 days, stimulated cells were harvested and stored at $-20{ }^{\circ} \mathrm{C}$ until the purification of $20 \mathrm{~S}$ proteasome (see above).

\section{Proteasome activity assay}

Five hundred nanogram of purified chicken proteasome was incubated with a fluorogenic peptide substrate at $37^{\circ} \mathrm{C}$, and fluorescence was measured as an indication of proteolytic cleavage at $360 \mathrm{~nm}$ excitation and $465 \mathrm{~nm}$ emission for the fluorophore 7-amino-4-methylcoumarin (AMC) and at $340 \mathrm{~nm}$ excitation and $405 \mathrm{~nm}$ emission for the fluorophore $\beta$-naphthylamide ( $\beta N A$ ). Fluorogenic substrates (Suc-LLVYAMC, Bz-VGR-AMC, Ac-YVAD-AMC, Z-LLE- $\beta$ NA; Bachem) were dissolved in DMSO and used at a final concentration of $100 \mu \mathrm{M}$. Activity assays were performed as previously described (Basler and Groettrup 2012). Using the proteasome inhibitor MG-132, proteasome and inhibitor were preincubated for $30 \mathrm{~min}$ at $37^{\circ} \mathrm{C}$ before adding the respective fluorogenic substrates. Fluorescence signals are given as signal above the autofluorescence of each substrate. Data are shown as mean $\pm \mathrm{SD}$ of triplicates or two experiments performed in triplicate.

\section{Results}

Identification of chicken proteasome subunits in different organs or cell types

Purified 20S proteasome from the 18-month-old chicken brain and spleen was separated by $2 \mathrm{D}$ non-equilibrium $\mathrm{pH}$ gradient gel electrophoresis (NEPHGE)-SDS-PAGE, and protein spots were visualized by Coomassie staining. As shown in the $2 \mathrm{D}$ gel in Fig. 1a, the different chicken proteasomes possess high similarity in the numbers and migratory positions of protein spots and the proteasome subunits are distributed over the same isoelectric point $(\mathrm{pI})$ as for human and murine 


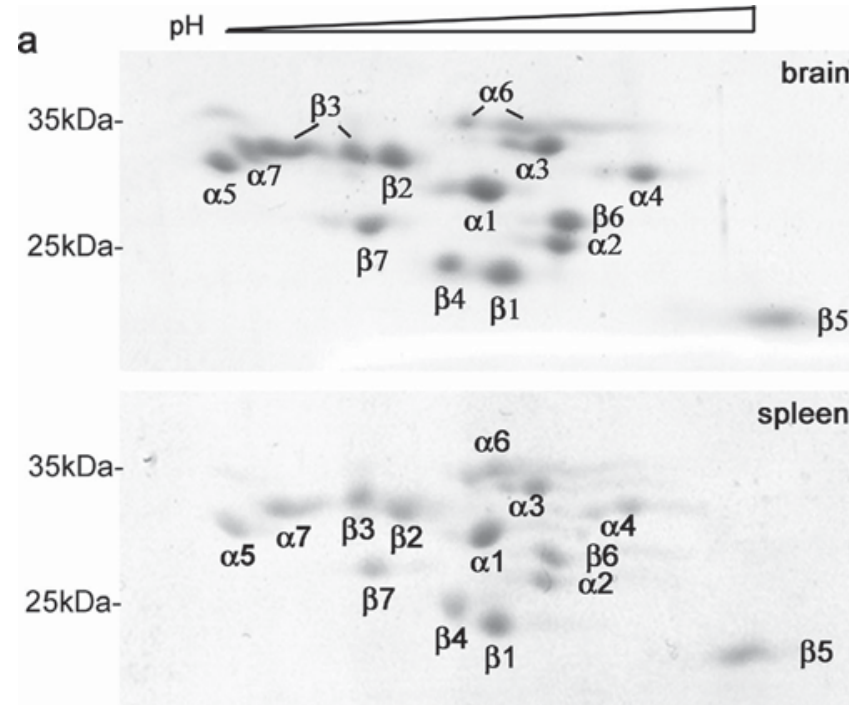

Fig. 1 Two dimensional gel electrophoresis and mass spectrometric analysis of purified chicken $20 \mathrm{~S}$ proteasomes. $20 \mathrm{~S}$ proteasome purified from the 18 month old chicken a brain and spleen and $\mathbf{b}$ blood and 7 week old bursa of Fabricius as indicated were separated by two dimensional non equilibrium $\mathrm{pH}$ gradient gel electrophoresis (NEPHGE)/SDS PAGE, and proteasome subunits were visualized by Coomassie blue staining. a For the identification of the subunits, 18

proteasome. In complete brain tissue of the mouse, only constitutive 20S proteasome is visible in Coomassie-stained 2D gels (Kremer et al. 2010). In contrast to the chicken spleen, in the mouse spleen, about equal amounts of constitutive $20 \mathrm{~S}$ proteasome and 20S immunoproteasome was found and the immunoproteasome subunits $\beta 1 \mathrm{i}$ (LMP2), $\beta 2 \mathrm{i}$ (MECL-1), and $\beta 5 \mathrm{i}$ (LMP7) were readily visible on Coomassie-stained $2 \mathrm{D}$ gels and easily distinguished from the constitutive subunits $\beta 1, \beta 2$, and $\beta 5$ due to marked differences in molecular mass and/or isoelectric point (Groettrup et al. 1996; Khan et al. 2001; Kremer et al. 2010). To identify the subunits of chicken 20S proteasome from the brain and spleen and to exclude that putative immunosubunits migrated equally as constitutive ones, 18 spots were excised from 2D gels and were analyzed by mass spectrometry. We were able to identify all 14 different subunits of the chicken $20 \mathrm{~S}$ proteasome including the catalytically active subunits $\beta 2$ and $\beta 5$, but not the third catalytic subunit $\beta 1$ (Table 1 and Fig. 1a). There is no available sequence for chicken $\beta 1$ in the database; therefore, we first blasted murine $\beta 1$ versus the chicken ESTs database (PubMed) and identified the cDNA sequence BX933198.1, which has all highly conserved amino acids typical for the catalytically active subunit $\beta 1$ (Huber et al. 2012). By MS analysis, $\beta 5$ was identified as hypothetical protein RCJMB04 14i9 (Swiss-Prot database), which is $100 \%$ identical to proteasome subunit alpha type-5 [Gallus gallus] (NCBI Reference Sequence: NP 001026578.1 ; refseq protein database). In Fig. 1a, the $2 \mathrm{D}$ gels are depicted with the assignments of the identified proteasome subunits.
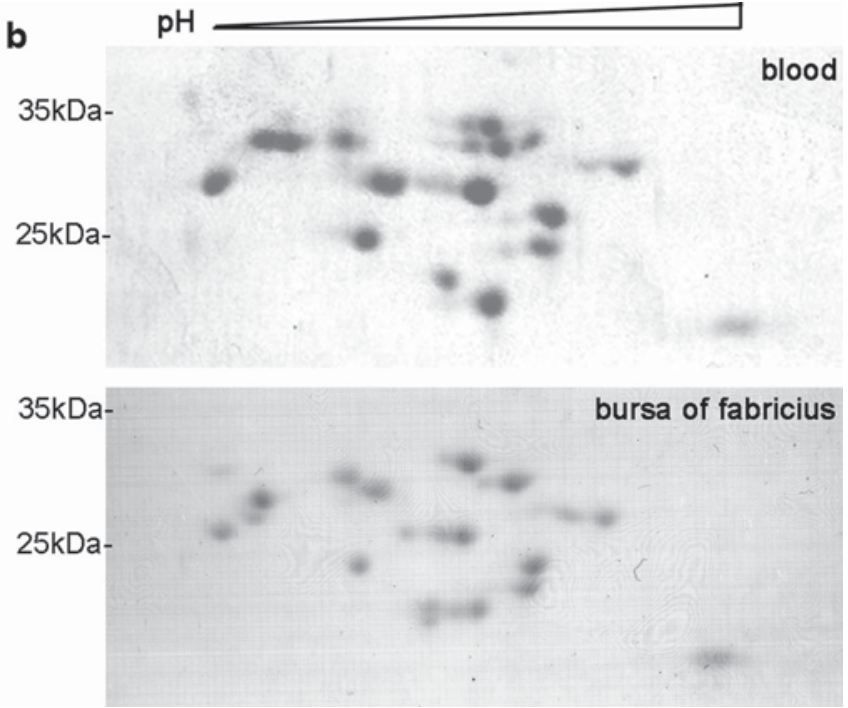

visible spots were excised and analyzed by nano LC ESI MS/MS. Some subunits were identified in two nearby spots, e.g., $\alpha 3, \alpha 6, \alpha 4$, and $\beta 3$ which might be a sign of post translational modifications changing the migratory properties. b Purifications of $20 \mathrm{~S}$ proteasome from whole blood and the bursa of Fabricius. In general, 20S proteasome from all four tissues showed similar protein spot patterns

Not all values for the molecular weights and isoelectric points of the subunits are conforming with the spot distribution in the 2D gel, but this is not unexpected because they were only predicted and not experimentally determined (compare Table 1 to Fig. 1a). All 14 identified proteasome subunits were in line with previously published data of an MS analysis performed with 20S proteasome from chicken skeletal muscle (Hayter et al. 2005). So far, we could conclude that in contrast to the human and the mouse, the brain and spleen from chicken revealed virtually identical protein spot patterns in their $20 \mathrm{~S}$ proteasomes.

To further address this issue, 2D gel electrophoresis of $20 \mathrm{~S}$ proteasomes from the chicken whole blood (18 months) and bursa of Fabricius (7 weeks) was performed in order to determine the migratory pattern of these $20 \mathrm{~S}$ proteasome subunits. Whole blood is expected to mainly contain constitutive proteasome due to the predominance of erythrocytes, while the bursa of Fabricius consists mostly of B cells and therefore is suspected to express immunoproteasome. Spot patterns from both samples showed high similarity, and MS analysis revealed also no difference in protein composition (Fig. 1b). Finally, the $20 \mathrm{~S}$ proteasome from the thymus and brain of the same 10-week-old chicken was compared in a 2D gel analysis. The brain sample served as an example of constitutive proteasome, and the thymus, which is the place of $\mathrm{T}$ cell selection until sexual maturity, is supposed to express mostly immunoproteasome. Here, as well, no differences in 
Table 1 Identification of 20S proteasome subunits by mass spectrometry (coverage indicated in percent for brain (top) and spleen (bottom))

\begin{tabular}{|c|c|c|c|c|c|}
\hline Subunit & Accession & Description & $\begin{array}{l}\mathrm{MW} \\
(\mathrm{kDa})\end{array}$ & $\begin{array}{l}\text { Calc. } \\
\text { pI }\end{array}$ & Coverage \\
\hline$\alpha 1$ & F1NEQ6 & $\begin{array}{l}\text { Proteasome subunit alpha type (fragment) } \\
\text { [Gallus gallus }] \text { PSMA6 }\end{array}$ & 27.7 & 6.55 & $\begin{array}{l}47.8 \% \\
36.6 \%\end{array}$ \\
\hline$\alpha 2$ & E1C006 & $\begin{array}{l}\text { Proteasome subunit alpha type [Gallus gallus] } \\
\text { PSMA2 }\end{array}$ & 25.9 & 7.49 & $\begin{array}{l}54.3 \% \\
48.7 \%\end{array}$ \\
\hline$\alpha 3$ & $\mathrm{~F} 1 \mathrm{NC} 02$ & $\begin{array}{l}\text { Proteasome subunit alpha type (fragment) } \\
\text { [Gallus gallus] PSMA4 }\end{array}$ & 29.5 & 7.33 & $\begin{array}{l}60.5 \% \\
59.7 \%\end{array}$ \\
\hline$\alpha 4$ & F1NWM1 & $\begin{array}{l}\text { Proteasome subunit alpha type } 7 \text { (fragment) } \\
\text { [Gallus gallus] PSMA7 }\end{array}$ & 24.3 & 8.7 & $\begin{array}{l}58.3 \% \\
59.7 \%\end{array}$ \\
\hline$\alpha 5$ & Q5ZJX9 & $\begin{array}{l}\text { Proteasome subunit alpha type [Gallus gallus] } \\
\text { RCJMB04_14i9/PSMA5 }\end{array}$ & 26.4 & 4.82 & $\begin{array}{l}63.5 \% \\
61.0 \%\end{array}$ \\
\hline$\alpha 6$ & F1NFI8 & $\begin{array}{l}\text { Proteasome subunit alpha type [Gallus gallus] } \\
\text { PSMA1 }\end{array}$ & 29.3 & 6.54 & $\begin{array}{l}51.7 \% \\
73.9 \%\end{array}$ \\
\hline$\alpha 7$ & Q5ZLI2 & $\begin{array}{l}\text { Proteasome subunit alpha type [Gallus gallus] } \\
\text { PSMA3 }\end{array}$ & 28.5 & 5.05 & $\begin{array}{l}21.6 \% \\
27.8 \%\end{array}$ \\
\hline$\beta 1$ & BX933198.1 & Gallus gallus finished cDNA, clone ChEST511c20 & 27.2 & 5.91 & $\begin{array}{l}52.1 \% \\
50.6 \%\end{array}$ \\
\hline$\beta 2$ & Q7ZT63 & $\begin{array}{l}\text { Proteasome subunit beta type [Gallus gallus] } \\
\text { cpsmb7 }\end{array}$ & 29.9 & 6.4 & $\begin{array}{l}46.2 \% \\
42.6 \%\end{array}$ \\
\hline$\beta 3$ & E1BYW9 & $\begin{array}{l}\text { Proteasome subunit beta type [Gallus gallus] } \\
\text { PSMB3 }\end{array}$ & 23.1 & 5.41 & $\begin{array}{l}40.0 \% \\
36.6 \%\end{array}$ \\
\hline$\beta 4$ & F1NZ80 & $\begin{array}{l}\text { Proteasome subunit beta type (fragment) } \\
\quad \text { [Gallus gallus }] \text { PSMB2 }\end{array}$ & 23.7 & 7.97 & $\begin{array}{l}58.6 \% \\
58.1 \%\end{array}$ \\
\hline$\beta 5$ & P34065 & $\begin{array}{l}\text { Proteasome subunit beta type } 5 \text { (fragment) [Gallus } \\
\text { gallus] PSMB5 }\end{array}$ & 27 & 8.68 & $\begin{array}{l}45.3 \% \\
49.2 \%\end{array}$ \\
\hline$\beta 6$ & Q6JLB2 & $\begin{array}{l}\text { Proteasome subunit beta type [Gallus gallus] } \\
\text { PSMB1 }\end{array}$ & 26 & 6.89 & $\begin{array}{l}44.7 \% \\
35.9 \%\end{array}$ \\
\hline$\beta 7$ & H9L0U6 & $\begin{array}{l}\text { Proteasome subunit beta type [Gallus gallus] } \\
\text { PSMB4 }\end{array}$ & 28.1 & 5.97 & $\begin{array}{l}38.0 \% \\
36.4 \%\end{array}$ \\
\hline
\end{tabular}

the spot distribution were observed and this was also confirmed by MS analysis (Fig. 2). This implicates that chicken expresses constitutive proteasome, but apparently does not produce immunoproteasome in lymphoid tissues.

Immune stimulation of chicken spleen cells

Given that immunoproteasome expression can be induced by inflammatory cytokines like IFN- $\gamma$ and TNF- $\alpha$, chicken splenocytes were incubated with different stimuli, thereby promoting the immunoproteasome expression if the corresponding genes were present in the avian genome. The induction of IFN- $\gamma$ was assessed $24 \mathrm{~h}$ after stimulation by real-time RT-PCR, and the highest amount of IFN- $\gamma$ mRNA was recorded in spleen cells treated with PMA/ionomycin and concanavalin A, while LPS had no effect (Fig. 3b). During stimulation, we observed that PMA/ionomycin treatment resulted in cell proliferation as an indication of an ongoing inflammatory response. This was shown by CFSE dilution assay with spleen cells which were analyzed $72 \mathrm{~h}$ after stimulation (Fig. 3a).

After 3 days of stimulation with PMA/ionomycin, spleen cells were harvested for $20 \mathrm{~S}$ proteasome purification and were analyzed by 2D gel electrophoresis in comparison to unstimulated spleen cells. The separation by $2 \mathrm{D}$ gel electrophoresis of unstimulated versus stimulated samples displayed the same subunit patterns after Coomassie blue-staining (Fig. 3c). Comparing Fig. 3c to Figs. 1 and 2, this protein pattern is similar to that before described for the bursa of Fabricius, brain, and whole blood cells. Interestingly, a new spot appeared on the 2D gel with the same molecular weight as $\beta 5$, but a bit less alkaline, which is maybe due to phosphorylation or acetylation (Moiseeva et al. 2013) of the subunit. Taken together, it appears that stimulation of spleen cells with PMA/ionomycin, which induced lymphocyte proliferation, did not provide any evidence for the induction of immunoproteasomes. 


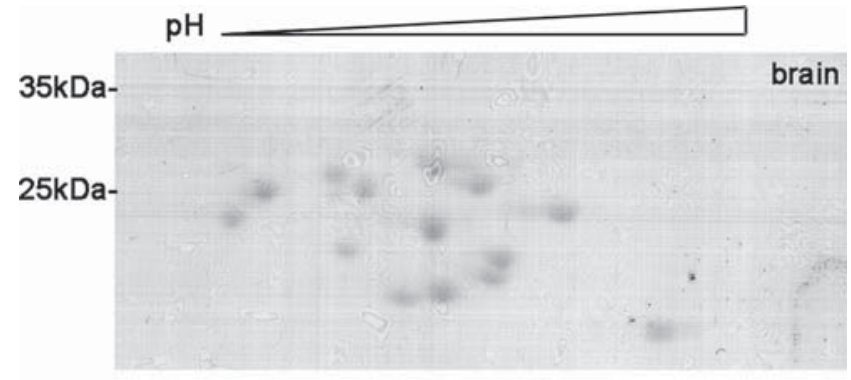

$35 \mathrm{kDa}-$

thymus

$25 \mathrm{kDa}-$

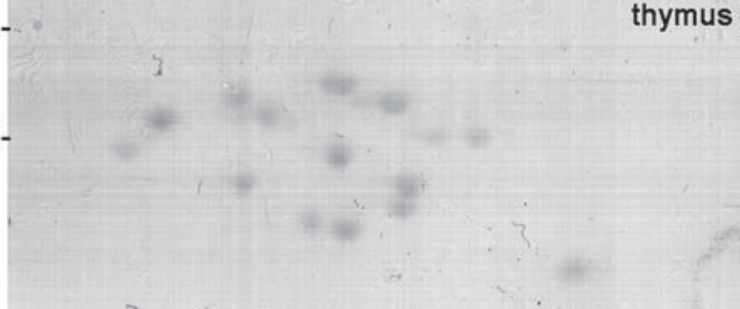

Fig. 2 Two dimensional gel electrophoresis of 20S proteasomes purified from the chicken brain and thymus. The brain and thymus were taken from the same 10 week old chicken, and purified 20S proteasome was separated by NEPHGE/SDS PAGE. The protein spots were visualized by Coomassie blue staining

Proteolytic activity of chicken proteasome from different organs and cell types

Typically, the constitutive proteasome in humans and mice has three catalytically active subunits, which possess different cleavage properties, in particular, trypsin-, caspase-, and chymotrypsin-like activities. To compare the proteolytic cleavage of all purified $20 \mathrm{~S}$ proteasomes from the different chicken tissues, the respective $20 \mathrm{~S}$ proteasomes were incubated with the fluorogenic substrates Suc-LLVY-AMC, BzVGR-AMC, Ac-YVAD-AMC, and Z-LLE- $\beta N A$, to follow chymotrypsin-, trypsin-, and caspase-like activities, respectively, by measuring the fluorescence of the free leaving groups AMC and $\beta \mathrm{NA}$. In general, the chicken proteasomes from different organs possessed all the three tested proteolytic activities to a similar extent (Fig. 4a). Notably, for the whole blood $20 \mathrm{~S}$ proteasome, the trypsin-like activity was nearly twice as high compared to the other proteasomes and proteolytic activities. The chymotrypsin- and caspase-like activities were similar between proteasomes from the brain, whole blood, bursa of Fabricius, spleen, or thymus, while the human 20S immunoproteasome purified from the $\mathrm{T}$ cell lymphoblastoid line LCL721-145 (Salter and Cresswell 1986), which was tested in parallel, showed a strongly reduced caspase-like activity as would be expected for the replacement of $\beta 1$ with $\beta 1$ i (LMP2) (Khan et al. 2001). In contrary, 20S constitutive proteasome from the $\beta 1 \mathrm{i}$ - and $\beta 5 \mathrm{i}$ deficient T cell lymphoblastoid line LCL721-174 (Salter and Cresswell 1986) showed very high caspase-like cleavage activity.

To further characterize the five different chicken proteasomes, we used the well-known broad spectrum proteasome inhibitor MG-132 which inhibits all activities of the 20S proteasome. At a concentration of $10 \mu \mathrm{M}, \mathrm{MG}-132$ led to a marked decrease of the cleavage of Suc-LLVY-AMC substrate by human constitutive and immunoproteasome and

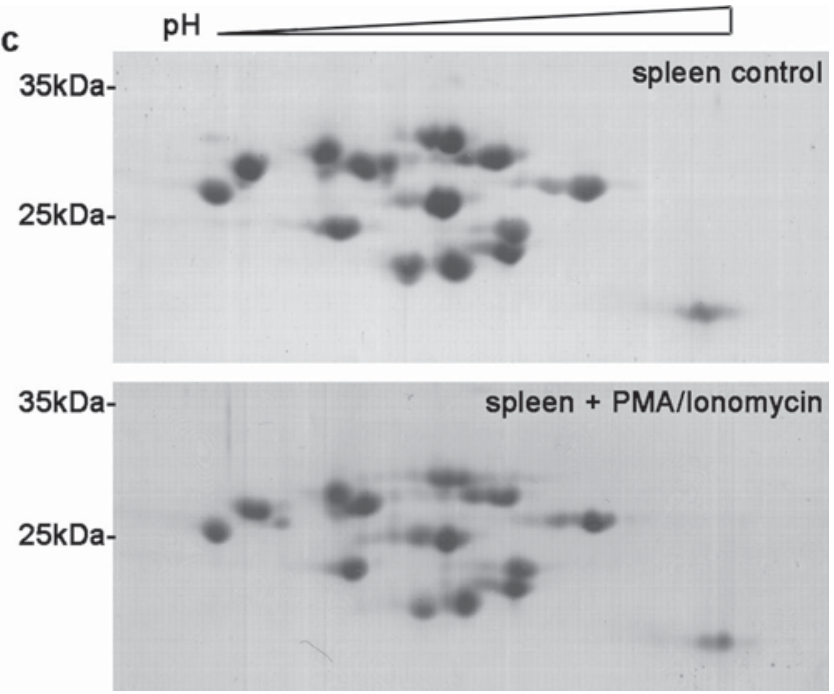

the chicken spleen single cell suspension either left unstimulated or stimulated. Seven spleens were dissected from 7 week old chicken, followed by the preparation of single cell suspensions. One half of the cells was not stimulated and was immediately frozen. The other half was seeded for stimulation with $10 \mathrm{ng} / \mathrm{ml}$ PMA and $0.5 \mu \mathrm{g} / \mathrm{ml}$ ionomycin and was incubated for 3 days at $37^{\circ} \mathrm{C}$. Proteasome subunits were separated by
Fig. 3 Stimulation of a chicken spleen single cell suspension with PMA ionomycin, concanavalin A and lipopolysaccharide (LPS). a Proliferation of spleen cells was investigated by CFSE dilution assay $48 \mathrm{~h}$ after adding the indicated stimuli. b The induction of INF $\gamma$ mRNA was analyzed $24 \mathrm{~h}$ after stimulation of spleen cells. Data are shown as mean \pm SD of tripli cates normalized to GAPDH from two different experiments. c Two dimensional gel electrophoresis of $20 \mathrm{~S}$ proteasomes purified from
NEPHGE/SDS PAGE and were visualized by Coomassie blue staining

b
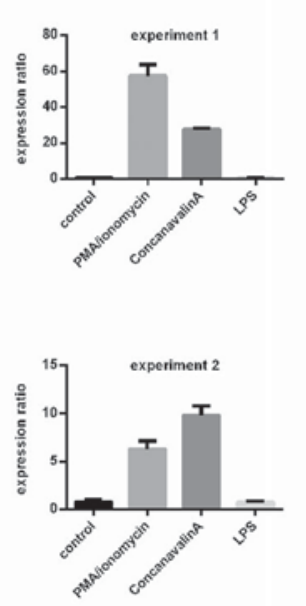
a
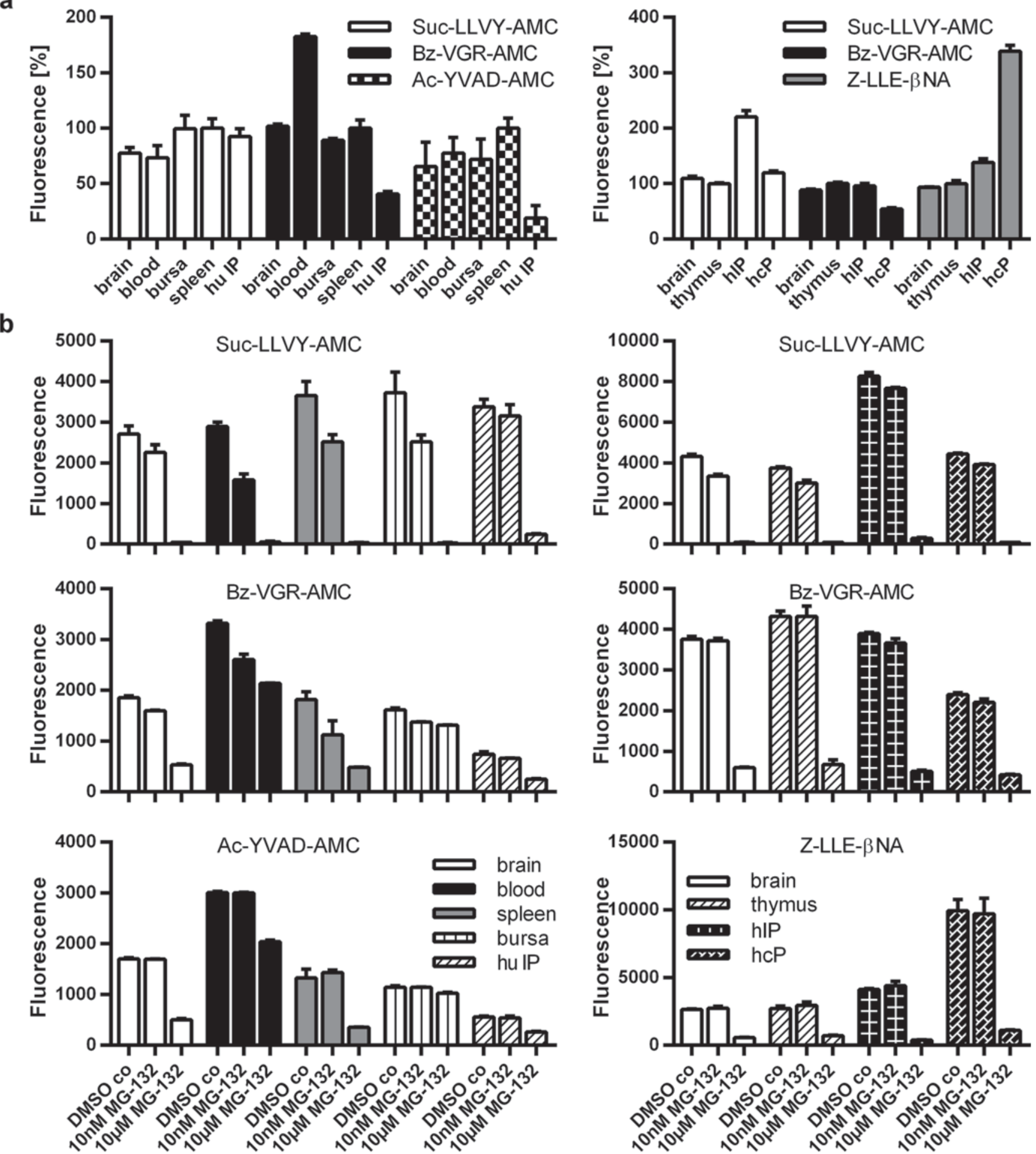

Fig. 4 Proteolytic activity of chicken 20S proteasomes purified from the brain, whole blood, bursa of Fabricius, spleen, and thymus in comparison to human immunoproteasome $(h I P)$ and human constitutive proteasome $(h c P)$. a $20 \mathrm{~S}$ proteasomes were incubated for $1 \mathrm{~h}$ at $37{ }^{\circ} \mathrm{C}$ with the fluorogenic peptide substrates Suc LLVY AMC, Bz VGR AMC, Ac YVAD AMC, and Z LLE $\beta N A$ to follow their chymotrypsin, trypsin , and caspase like cleavage properties, respectively. The substrate hydrolysis was measured in triplicate; fluorescence is depicted as signal above background (substrate without proteasome) and normalized to

spleen (left panel) or thymus (right panel). b The experiment was performed as described in (a), but before adding the substrates, 20S proteasomes were incubated for $30 \mathrm{~min}$ with the indicated concentrations of the proteasome inhibitor MG 132. The upper panel shows chymotrypsin like activity, the middle panel trypsin like activity, and in the lower panel, the caspase like cleavage activity is depicted. The assay was performed in triplicate and fluorescence signals are given as signal above background. Data are shown as mean $\pm \mathrm{SD}$ of triplicates 
chicken proteasomes, while the inhibition of the cleavage of Bz-VGR-AMC, Ac-YVAD-AMC, and Z-LLE- $\beta N A$ substrates was somewhat less prominent (Fig. 4b).

\section{Discussion}

In jawed vertebrates, the immunoproteasome is expressed constitutively in lymphocytes and monocytes or can be induced by IFN- $\gamma$ treatment. Together with MHC- and T/B cell receptor-based adaptive immunity, the immunoproteasome evolved and seemed to disappear in the lineage of aves (Sutoh et al. 2012). With the aim of investigating the presence of the constitutive and immunoproteasome in chicken, we purified 20S proteasomes from different lymphoid and nonlymphoid organs. Furthermore, the subunits of these proteasomes were separated by $2 \mathrm{D}$ gel electrophoresis and the protein spots from proteasome purified from the brain and spleen were identified by mass spectrometry. All spots between 20 and $30 \mathrm{kDa}$ were matched to proteasomal subunits, indicating the purity of the preparations, and altogether, 14 subunits were identified in chicken as already found in humans, mice, and rats (Claverol et al. 2002; Froment et al. 2005; Schmidt et al. 2006). Actually, the number of excised spots exceeded that of the proteasome subunits by 4 , indicating that some proteins might be post-translationally modified, e.g., by glycosylation, phosphorylation, acetylation, or deamination and therefore have different properties, e.g., a different isoelectric point. This was confirmed by the finding that some subunits were found in two juxtaposed protein spots, e.g., $\alpha 3$, $\alpha 6, \alpha 4$, and $\beta 3$. The identification of all 14 subunits and also the organization of protein spots on the 2D gel, which depends on the molecular weight and isoelectric point, are in line with the publication of Hayter et al. (2005). They showed the 2D gel analysis of 20S proteasome purified from chicken skeletal muscle and also identified the proteasomal subunits by a combination of MALDI-TOF peptide mass fingerprinting and de novo sequencing by MS/MS analysis, but had problems with the assignment because the chicken genome sequences for the proteasomal subunits were not available at that time (Hayter et al. 2005). We found that the protein spot pattern of $20 \mathrm{~S}$ proteasome purified from the brain was similar to that of the spleen, although it is expected that constitutive proteasome is found in the brain and immunoproteasome in the spleen, which can be easily detected due to obvious and consistent differences in the spot arrangement in the 2D gel (Groettrup et al. 1996). After exhaustive MS analysis of deviant protein spots, we concluded that neither for the brain and spleen nor for the whole blood, bursa of Fabricius, and thymus could any difference be detected, indicating that immunoproteasome is not expressed in chicken.
To further challenge the proposed lack of immunoproteasomes in chicken, spleen cells were stimulated with PMA/ionomycin aiming at the induction of immunoproteasome. For chicken erythrocytes, thrombocytes as well as bone-marrow-derived DCs, macrophages, and monocyte-derived macrophages, it was already shown that they react to immune stimuli by, e.g., up- or downregulation of chemokine receptors and induction of IFN- $\gamma$ (Morera et al. 2011; St Paul et al. 2012a; St Paul et al. 2012b; St Paul et al. 2012c; Wu and Kaiser 2011). We could confirm that chicken spleen cells incubated with PMA/ionomycin and concanavalin A showed an induction of IFN- $\gamma$ mRNA and the stimulation was further documented by a strong cell proliferation after PMA/ionomycin treatment. Despite the proliferation of the spleen cells which is a reliable sign for lymphocyte activation, the subunit composition of $20 \mathrm{~S}$ proteasome purified from stimulated cells looked almost identical to that of unstimulated cells.

Since we could not observe any reasonable hint for the presence of immunoproteasome in chicken by 2D gel analysis, our next approach was to check the catalytic activities of the different proteasomes. Human and murine constitutive proteasome has three different proteolytic sites for chymotrypsin-, trypsin-, and caspase-like activities. Upon the induction of the immunoproteasome, the proteolytic properties change and thereby the caspase-like activity is dramatically decreased. The change of the cleavage properties was followed by the use of three fluorogenic proteasomal substrates with hydrophobic (Suc-LLVY-AMC), basic (Bz-VGR-AMC), and acidic (Ac-YVAD-AMC, Z-LLE- $\beta N A$ ) amino acid residues in the $\mathrm{P} 1$ position. The chymotrypsin-like cleavage activity examined by the substrate Suc-LLVY-AMC showed no significant change between chicken proteasomes from lymphoid and non-lymphoid tissues, and the same was observed for the caspase-like activity (Ac-YVAD-AMC, Z-LLE- $\beta N A$ ). Since the caspase-like activity is strongly downregulated upon the replacement of constitutive proteasomes by immunoproteasomes in the mouse and human (Groettrup et al. 1996), the absence of such a change when comparing proteasome from the chicken brain and spleen already strongly suggests that no immunoproteasome is present in the chicken spleen, bursa of Fabricius, or thymus. After the duck genome was reported last year, we blasted the available sequences for the immunosubunits $\beta 1 \mathrm{i}, \beta 2 \mathrm{i}$, and $\beta 5 \mathrm{i}$ as well as the thymus-specific subunit $\beta 5 \mathrm{t}$, but these subunits were not detectable as already reported for Galliformes and zebra finch (Huang et al. 2013).

In humans and mice, the MHC class I molecule presents with a higher affinity for short peptides with hydrophobic or sometimes basic amino acid side chains at the carboxyl terminus. The production of such peptides is additionally increased through the induction of the immunoproteasome, implicating an important role of the immunoproteasome in the cytotoxic $\mathrm{T}$ 
lymphocyte responses. Consistently, chicken which lack the immunoproteasome in their genome and on protein level possesses MHC class I molecules, which accommodate peptides with acidic $\mathrm{C}$-terminal anchor residues. One could hence argue that in chicken, the caspase-like activity of constitutive proteasomes does not need to be downregulated for optimal production of MHC class I ligands.

Recently, however, new functions of the immunoproteasome, which are unrelated to antigen processing, have been discovered. The immunoproteasome was shown to support the development of inflammatory $\mathrm{T}$ helper cells of the Th1 and Th17 type and to promote the production of pro-inflammatory cytokine responses (Moebius et al. 2010; Muchamuel et al. 2009). The inhibitor ONX0914 (formerly named PR-957) irreversibly blocks the activity of the immunoproteasome subunit $\beta 5 \mathrm{i}$ in mice and humans. It suppresses the production of pro-inflammatory cytokines and the differentiation of Th1 and Th17 T helper cells while regulatory $\mathrm{T}$ cells are promoted and Th2 cells remain unaffected (Kalim et al. 2012; Muchamuel et al. 2009). In different mouse models, the treatment with ONX0914 suppressed autoimmune disease like rheumatoid arthritis, diabetes (Muchamuel et al. 2009), colitis (Basler et al. 2010), systemic lupus erythematosus (Ichikawa et al. 2012), and experimental autoimmune encephalomyelitis (Basler et al. 2014). Additionally, this is affirmed by reports that in humans, mutations in the gene encoding for $\beta 5 \mathrm{i}$ are associated with autoinflammatory disease (Agarwal et al. 2010; Arima et al. 2011; Kitamura et al. 2011). Apparently, the latter regulatory functions of immunoproteasomes are not required in the chicken immune system.

Another interesting aspect is that the whole lineage of birds seems to lack thymoproteasome, because the thymus-specific subunit $\beta 5 \mathrm{t}$ is missing in the genome (Sutoh et al. 2012). This 20S thymoproteasome which is only expressed by cortical thymic epithelial cells (cTECs) but not medullary TECs has changed catalytic properties and produces peptides that bind with a lower affinity to MHC class I molecules. The different proteasome species in cTECs and mTECs were proposed to generate differences in the pools of negatively and positively selecting MHC class I ligands needed for efficient $\mathrm{T}$ cell selection. Mice with a deletion of the subunit $\beta 5 \mathrm{t}$ were still able to perform the early selection of $\mathrm{T}$ cells but these animals formed a small and immune incompetent repertoire of $\mathrm{CD}^{+} \mathrm{T}$ cells which was reduced in number to $20-30 \%$ and were therefore hypersensitive to influenza virus infections (Nitta et al. 2010). The question arises, how do chickens or birds compensate for the lack of immuno- and thymoproteasome and what does this mean to our understanding of the function of these proteasomes in thymic selection. Clearly, a more detailed study of $\mathrm{T}$ cell selection in birds is warranted.
Acknowledgments We thank Gerardo Alvarez Salinas, Gerhard Gröttrup, and Lars Krieger for their help with proteasome purification and Thomas Göbel (LMU Munich) and Jim Kaufman (Cambridge University) for helpful advice concerning the spleen stimulation experi ments. We are grateful to Julia Koerner and Michael Basler for help with flow cytometric analyses. The team of the animal research facility of Konstanz University is acknowledged for assistance during animal ex perimentation. This work was supported by a grant from the German Research Foundation (Nr. GR 1517/14 1) and a grant from the Swiss National Science Foundation (Nr. 31003A_138451).

\section{References}

Agarwal AK, Xing C, DeMartino GN, Mizrachi D, Hernandez MD, Sousa AB, Martinez de Villarreal L, dos Santos HG, Garg A (2010) PSMB8 encoding the beta5i proteasome subunit is mutated in joint contractures, muscle atrophy, microcytic anemia, and panniculitis induced lipodystrophy syndrome. Am J Hum Genet $87: 866872$

Arima K, Kinoshita A, Mishima H, Kanazawa N, Kaneko T, Mizushima T, Ichinose K, Nakamura H, Tsujino A, Kawakami A, Matsunaka M, Kasagi S, Kawano S, Kumagai S, Ohmura K, Mimori T, Hirano M, Ueno S, Tanaka K, Tanaka M, Toyoshima I, Sugino H, Yamakawa A, Niikawa N, Furukawa F, Murata S, Eguchi K, Ida H, Yoshiura K (2011) Proteasome assembly defect due to a protea some subunit beta type 8 (PSMB8) mutation causes the autoinflammatory disorder, Nakajo Nishimura syndrome. Proc Natl Acad Sci U S A 108:14914 14919

Balakrishnan CN, Ekblom R, Volker M, Westerdahl H, Godinez R, Kotkiewicz H, Burt DW, Graves T, Griffin DK, Warren WC, Edwards SV (2010) Gene duplication and fragmentation in the zebra finch major histocompatibility complex. BMC Biol 8:29

Basler M, Groettrup M (2012) Immunoproteasome specific inhibitors and their application. Methods Mol Biol 832:391 401

Basler M, Dajee M, Moll C, Groettrup M, Kirk CJ (2010) Prevention of experimental colitis by a selective inhibitor of the immunoproteasome. J Immunol 185:634 641

Basler M, Mundt S, Muchamuel T, Moll C, Jiang J, Groettrup M, Kirk CJ (2014) Inhibition of the immunoproteasome ameliorates experimen tal autoimmune encephalomyelitis. EMBO Mol Med 6:226 238

Chaves LD, Krueth SB, Reed KM (2009) Defining the turkey MHC: sequence and genes of the B locus. J Immunol 183:6530 6537

Claverol S, Burlet Schiltz O, Girbal Neuhauser E, Gairin JE, Monsarrat B (2002) Mapping and structural dissection of human $20 \mathrm{~S}$ protea some using proteomic approaches. Mol Cell Proteomics 1:567 578

Froment C, Uttenweiler Joseph S, Bousquet Dubouch MP, Matondo M, Borges JP, Esmenjaud C, Lacroix C, Monsarrat B, Burlet Schiltz O (2005) A quantitative proteomic approach using two dimensional gel electrophoresis and isotope coded affinity tag labeling for study ing human 20S proteasome heterogeneity. Proteomics 5:2351 2363

Groettrup M, Ruppert T, Kuehn L, Seeger M, Standera S, Koszinowski U, Kloetzel PM (1995) The interferon gamma inducible $11 \mathrm{~S}$ regu lator (PA28) and the LMP2/LMP7 subunits govern the peptide production by the $20 \mathrm{~S}$ proteasome in vitro. J Biol Chem 270: 2380823815

Groettrup M, Kraft R, Kostka S, Standera S, Stohwasser R, Kloetzel PM (1996) A third interferon gamma induced subunit exchange in the 20S proteasome. Eur J Immunol 26:863 869

Hayter JR, Doherty MK, Whitehead C, McCormack H, Gaskell SJ, Beynon RJ (2005) The subunit structure and dynamics of the 20S proteasome in chicken skeletal muscle. Mol Cell Proteomics 4: 13701381 
Hershko A, Ciechanover A, Varshavsky A (2000) Basic Medical Research Award. The ubiquitin system. Nat Med 6:1073 1081

Huang Y, Li Y, Burt DW, Chen H, Zhang Y, Qian W, Kim H, Gan S, Zhao Y, Li J, Yi K, Feng H, Zhu P, Li B, Liu Q, Fairley S, Magor KE, Du Z, Hu X, Goodman L, Tafer H, Vignal A, Lee T, Kim KW, Sheng Z, An Y, Searle S, Herrero J, Groenen MA, Crooijmans RP, Faraut T, Cai Q, Webster RG, Aldridge JR, Warren WC, Bartschat S, Kehr S, Marz M, Stadler PF, Smith J, Kraus RH, Ren L, Fei J, Morisson M, Kaiser P, Griffin DK, Rao M, Pitel F, Wang J, Li N (2013) The duck genome and transcriptome provide insight into an avian influenza virus reservoir species. Nat Genet 45:776 783

Huber EM, Basler M, Schwab R, Heinemeyer W, Kirk CJ, Groettrup M, Groll M (2012) Immuno and constitutive proteasome crystal struc tures reveal differences in substrate and inhibitor specificity. Cell 148:727 738

Ichikawa HT, Conley T, Muchamuel T, Jiang J, Lee S, Owen T, Barnard J, Nevarez S, Goldman BI, Kirk CJ, Looney RJ, Anolik JH (2012) Beneficial effect of novel proteasome inhibitors in murine lupus via dual inhibition of type I interferon and autoantibody secreting cells. Arthritis Rheum 64:493 503

Kalim KW, Basler M, Kirk CJ, Groettrup M (2012) Immunoproteasome subunit LMP7 deficiency and inhibition suppresses Th1 and Th17 but enhances regulatory T cell differentiation. J Immunol 189:4182 4193

Kaufman J (2008) The Avian MHC. In: Davison F, Kaspers B, Schat KA (eds) Avian immunology, 1st edn. Elsevier Ltd., London, pp 159181

Kaufman J, Volk H, Wallny HJ (1995) A "minimal essential Mhc" and an "unrecognized Mhc": two extremes in selection for polymorphism. Immunol Rev 143:63 88

Kaufman J, Milne S, Gobel TW, Walker BA, Jacob JP, Auffray C, Zoorob R, Beck S (1999) The chicken B locus is a minimal essential major histocompatibility complex. Nature 401:923 925

Khan S, van den Broek M, Schwarz K, de Giuli R, Diener PA, Groettrup M (2001) Immunoproteasomes largely replace constitutive proteasomes during an antiviral and antibacterial immune response in the liver. J Immunol 167:6859 6868

Kitamura A, Maekawa Y, Uehara H, Izumi K, Kawachi I, Nishizawa M, Toyoshima Y, Takahashi H, Standley DM, Tanaka K, Hamazaki J, Murata S, Obara K, Toyoshima I, Yasutomo K (2011) A mutation in the immunoproteasome subunit PSMB8 causes autoinflammation and lipodystrophy in humans. J Clin Invest 121:4150 4160

Kniepert A, Groettrup M (2014) The unique functions of tissue specific proteasomes. Trends Biochem Sci 39:17 24

Koch M, Camp S, Collen T, Avila D, Salomonsen J, Wallny HJ, van Hateren A, Hunt L, Jacob JP, Johnston F, Marston DA, Shaw I, Dunbar PR, Cerundolo V, Jones EY, Kaufman J (2007) Structures of an MHC class I molecule from B21 chickens illustrate promiscuous peptide binding. Immunity 27:885 899

Kremer M, Henn A, Kolb C, Basler M, Moebius J, Guillaume B, Leist M, Van den Eynde BJ, Groettrup M (2010) Reduced immunoproteasome formation and accumulation of immunoproteasomal precursors in the brains of lymphocytic choriomeningitis virus infected mice. J Immunol 185:5549 5560

Miteva M, Keusekotten K, Hofmann K, Praefcke GJ, Dohmen RJ (2010) Sumoylation as a signal for polyubiquitylation and proteasomal degradation. Subcell Biochem 54:195 214

Moebius J, van den Broek M, Groettrup M, Basler M (2010) Immunoproteasomes are essential for survival and expansion of $\mathrm{T}$ cells in virus infected mice. Eur J Immunol 40:3439 3449

Moiseeva TN, Bottrill A, Melino G, Barlev NA (2013) DNA damage induced ubiquitylation of proteasome controls its proteolytic activ ity. Oncotarget 4:1338 1348

Morera D, Roher N, Ribas L, Balasch JC, Donate C, Callol A, Boltana S, Roberts S, Goetz G, Goetz FW, MacKenzie SA (2011) RNA Seq reveals an integrated immune response in nucleated erythrocytes. PLoS One 6:e26998

Muchamuel T, Basler M, Aujay MA, Suzuki E, Kalim KW, Lauer C, Sylvain C, Ring ER, Shields J, Jiang J, Shwonek P, Parlati F, Demo SD, Bennett MK, Kirk CJ, Groettrup M (2009) A selective inhibitor of the immunoproteasome subunit LMP7 blocks cytokine produc tion and attenuates progression of experimental arthritis. Nat Med 15:781 787

Murata S, Sasaki K, Kishimoto T, Niwa S, Hayashi H, Takahama Y, Tanaka K (2007) Regulation of CD8+ T cell development by thymus specific proteasomes. Science 316:1349 1353

Mustonen L, Alinikula J, Lassila O, Nera K P (2001) Bursa of Fabricius. eLS. John Wiley \& Sons, Ltd

Nitta T, Murata S, Sasaki K, Fujii H, Ripen AM, Ishimaru N, Koyasu S, Tanaka K, Takahama Y (2010) Thymoproteasome shapes immuno competent repertoire of CD8+ T cells. Immunity 32:29 40

Rodriguez Mendez AJ, Luna Acosta JL, Carranza M, Harvey S, Aramburo C, Luna M (2010) Growth hormone expression in stro mal and non stromal cells in the bursa of Fabricius during bursal development and involution: causal relationships? Gen Comp Endocrinol 167:297 307

Salter RD, Cresswell P (1986) Impaired assembly and transport of HLA $\mathrm{A}$ and B antigens in a mutant TxB cell hybrid. EMBO J 5:943 949

Schmidt F, Dahlmann B, Janek K, Kloss A, Wacker M, Ackermann R, Thiede B, Jungblut PR (2006) Comprehensive quantitative prote ome analysis of $20 \mathrm{~S}$ proteasome subtypes from rat liver by isotope coded affinity tag and $2 \mathrm{D}$ gel based approaches. Proteomics 6: 46224632

Schmidtke G, Aichem A, Groettrup M (2014) FAT10ylation as a signal for proteasomal degradation. Biochim Biophys Acta 1843:97 102

Shiina T, Shimizu S, Hosomichi K, Kohara S, Watanabe S, Hanzawa K, Beck S, Kulski JK, Inoko H (2004) Comparative genomic analysis of two avian (quail and chicken) MHC regions. J Immunol 172: 67516763

Shiina T, Briles WE, Goto RM, Hosomichi K, Yanagiya K, Shimizu S, Inoko H, Miller MM (2007) Extended gene map reveals tripartite motif, $\mathrm{C}$ type lectin, and Ig superfamily type genes within a subre gion of the chicken MHC B affecting infectious disease. J Immunol 178:7162 7172

St Paul M, Barjesteh N, Paolucci S, Pei Y, Sharif S (2012a) Toll like receptor ligands induce the expression of interferon gamma and interleukin 17 in chicken CD4+ T cells. BMC Res Notes 5:616

St Paul M, Paolucci S, Barjesteh N, Wood RD, Schat KA, Sharif S (2012b) Characterization of chicken thrombocyte responses to Toll like receptor ligands. PLoS One 7:e43381

St Paul M, Paolucci S, Read LR, Sharif S (2012c) Characterization of responses elicited by Toll like receptor agonists in cells of the bursa of Fabricius in chickens. Vet Immunol Immunopathol 149:237 244

Sutoh Y, Kondo M, Ohta Y, Ota T, Tomaru U, Flajnik MF, Kasahara M (2012) Comparative genomic analysis of the proteasome beta5t subunit gene: implications for the origin and evolution of thymoproteasomes. Immunogenetics 64:49 58

Wallny HJ, Avila D, Hunt LG, Powell TJ, Riegert P, Salomonsen J, Skjodt K, Vainio O, Vilbois F, Wiles MV, Kaufman J (2006) Peptide motifs of the single dominantly expressed class I molecule explain the striking MHC determined response to Rous sarcoma virus in chickens. Proc Natl Acad Sci U S A 103:1434 1439

Wang B, Ekblom R, Strand TM, Portela Bens S, Hoglund J (2012) Sequencing of the core MHC region of black grouse (Tetrao tetrix) and comparative genomics of the galliform MHC. BMC Genomics 13:553

Wu Z, Kaiser P (2011) Antigen presenting cells in a non mammalian model system, the chicken. Immunobiology 216:1177 1183 